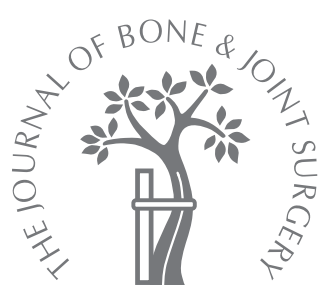

A. M. Foruria, M. M. de Gracia, D. R. Larson, L. Munuera, J. Sanchez-Sotelo

From La Paz University Hospital, Madrid, Spain and The Mayo Clinic, Rochester, Minnesota, United States

A. M. Foruria, MD, PhD Consultant Orthopaedic Surgeon

Department of Orthopaedic Surgery

Fundación Jiménez Díaz-Capio Avda Reyes Católicos 2, Madrid 28040, Spain

ㅍ. M. Me Gracia, MD, PhD Consultant Radiologist Department of Radiology La Paz University Hospital, Po de la Castellana 261, Madrid 28036, Spain

D. R. Larson, MS, Statistician Department of Biomedical Statistics and Infomatics II J. Sanchez-Sotelo, MD, PhD, Associate Professor

Mayo Clinic, 200 First Stree S. W., Rochester, Minnesota 55905, USA.

ㄴ. Munuera, MD, PhD, Emeritus Professor of Orthopaedics

Universidad Autónoma de Madrid, Arzobispo Morcillo 2, Madrid 28029, Spain.

Correspondence should be sent to $\operatorname{Dr}$ A. M. Foruria; e-mail: antonio.foruria@gmail.com

(C)2011 British Editorial Society of Bone and Joint Surgery doi:10.1302/0301-620X.93B3. $25083 \$ 2.00$

$J$ Bone Joint Surg $[\mathrm{Br}]$ 2011;93-B:378-86. Received 4 May 2010; Accepted after revision 23 November 2010

\title{
The pattern of the fracture and displacement of the fragments predict the outcome in proximal humeral fractures
}

\begin{abstract}
Our aim was to determine the effect of the initial pattern of fracture and the displacement of fragments on the outcome of proximal humeral fractures treated conservatively. We followed 93 consecutive patients prospectively for one year. Final movement and strength were compared with those of the contralateral side. The final American Shoulder and Elbow Society score and the Disabilities of Arm, Shoulder and Hand and Short-Form 36 questionnaires were compared with those provided by the patient on the day of the injury. Radiographs and CT scans with three-dimensional reconstruction were obtained in all patients. The pattern of the fracture and the displacement of individual fragments were analysed and correlated with the final outcome. There were two cases of nonunion and six of avascular necrosis. The majority of the fractures (84 patients; $90 \%$ ) followed one of the following four patterns: posteromedial (varus) impaction in 50 patients $(54 \%)$, lateral (valgus) impaction in $13(14 \%)$, isolated greater tuberosity in $15(16 \%)$, and anteromedial impaction fracture in six $(6 \%)$. Head orientation, impaction of the surgical neck and displacement of the tuberosity correlated strongly with the outcome.

In fractures with posteromedial impaction, a poor outcome was noted as the articular surface displaced inferiorly increasing its distance from the acromion. A poorer outcome was noted as a fractured greater tuberosity displaced medially overlapping with the posterior articular surface. Lateral impaction fractures had a worse outcome than other patterns of fracture.
\end{abstract}

The classification proposed by Neer ${ }^{1}$ has been used for decades to guide decisions as to treatment of fractures of the proximal humerus. ${ }^{2}$ However, the criteria were selected arbitrarily ${ }^{3}$ and at the time little attention was paid to the consequences of the injuries on the patientperceived quality of life. They were developed when advanced imaging methods, such as CT with three-dimensional (3D) reconstruction, were not available. Since then other authors have described patterns of fracture and fragments which were not initially included in Neer's classification. ${ }^{4,5}$

Although the displacement of the fracture is generally accepted to affect the outcome after conservative treatment of fractures of the proximal humerus, ${ }^{6}$ there is little information about the amount of displacement of each fragment which may be allowed to obtain a reasonably good result, and on the combined effect of the configuration of the fracture and the displacement upon the outcome. We hypothesised that the pattern of the fracture and the displacement of the fragments would influence the outcome, and that the initial findings would help to predict the function and loss of movement after conservative treatment. Our aim was to determine the relationship between the initial pattern and displacement of the fracture and the outcome in a consecutive group of patients treated conservatively.

\section{Patients and Methods}

After approval of the Institutional Review Board, all patients with a fracture of the proximal humerus evaluated at the Emergency Department of our hospital between March and September 2005 were considered for inclusion in the study. The on-call orthopaedic team recommended either conservative or surgical treatment based on the morphology of the fracture, the age of the patient, the functional demands and comorbidities. Patients selected for conservative treatment were asked to participate in the study if they were aged 18 years or older, had a unilateral fracture, had no other associated injuries or previous fracture involving the shoulder and had preserved cognitive function as determined by the Pfeiffer test. ${ }^{7}$ During this period 132 patients were evaluated, in whom surgical 
treatment was proposed and accepted in ten. Of the remaining 122, 111 fulfilled the inclusion criteria and were included in the study. All gave informed consent. Within the first 12 months after their fracture seven died as a result of unrelated causes and 11 were lost to follow-up. The remaining 93 patients were followed for one year and formed the basis of our study.

There were 73 women and 20 men with a mean age of 71 years (26 to 93). The cause of injury was a fall from standing height in $79(84.9 \%)$, a high-energy injury (motor-vehicle accident or a major fall from a height) in eight $(8.6 \%)$, and a sport-related injury in six $(6.5 \%)$. There was a history of previous pathology in the affected shoulder in 12 patients $(12.9 \%)$ for which none had required surgery. Comorbidities included heart disease in 16 patients $(17.2 \%)$, diabetes mellitus in ten $(10.8 \%)$, gastrointestinal disease in nine $(9.7 \%)$ and pulmonary disease in seven $(7.5 \%)$.

Protocol of treatment. The treatment was identical in all the patients. They were instructed and supervised by the same orthopaedic surgeon (AMF). No attempts at closed reduction were made. The affected upper limb was protected in a commercially available shoulder immobiliser for the first two weeks after the fracture. A home programme of passive and active assisted range-of-movement exercises was then initiated within the range of pain tolerance for four more weeks, protecting the arm in the sling between the exercise periods. Stretching exercises were added at six weeks and shoulder elevation, external and internal rotation elastic rubber-band strengthening exercises ${ }^{8}$ were started at 12 weeks and continued for three months.

Clinical evaluation. At the time of their first evaluation immediately after the fracture, the patients were requested to mark on a visual analogue scale (VAS), ranging from 0 to 10 , the mean level of shoulder pain which they had experienced during the six months before the fracture. They were also requested to complete the Disabilities of Arm, Shoulder and Hand (DASH) ${ }^{9}$ and the Short-Form (SF)-36 ${ }^{10}$ questionnaires, and the American Shoulder and Elbow Society (ASES) ${ }^{11}$ score was calculated to determine the functional status before the fracture. Active movement of the healthy shoulder was measured by a goniometer for elevation and external rotation, and internal rotation was determined as the highest spinal level reached by the thumb. Strength was also graded for the healthy shoulder on a scale from 1 to 5 , with 5 defining normal strength and 1 indicating paralysis.

The patients were then assessed at three, six and 12 months after their fracture for pain and satisfaction using the VAS, and for movement and strength bilaterally as detailed above. The DASH and SF-36 questionnaires were completed again and the ASES score was calculated. The results at 12 months were also graded as excellent, satisfactory or unsatisfactory using the modified Neer rating system. ${ }^{12}$ All clinical evaluations and gathering of data were performed by a single investigator (AMF).
Radiological evaluation. All radiographs were standardised according to an established protocol and carried out under direct supervision by the same physician (AMF). The projections included an anteroposterior (AP) radiograph in the plane of the scapula with the arm in $20^{\circ}$ of external rotation, a lateral ' $Y$ view' with the forearm parallel to the image receptor, and an axillary view taken with the patient standing with the $\mathrm{x}$-ray beam coming from the floor towards the axilla, and the image receptor over the patient's shoulder, the arm being separated from the body passively as in a pendulum exercise ${ }^{8}$ in order to obtain radiographs of good quality without excessive pain. Radiographs were obtained for both shoulders at the time of the fracture, and for the affected shoulder at three, six and 12 months. Additional AP and lateral radiographs were taken at two and six weeks to assess possible displacement. The affected shoulders were also evaluated by CT including $3 \mathrm{D}$ and threeplanar reconstruction referenced to the scapular plane, immediately after the injury and at 12 months.

All the digital radiographs and CT scans were corrected for magnification and the morphology of each individual fracture was analysed based on these, including spatial rotation of 3D reconstructions. Commercially available software (Autocad 2004; Autodesk Inc., San Rafael, California) was used to calculate the measurements listed in Table I for both the radiographs and the CT reconstructions (Fig. 1). The diaphyseal axis was used to define inferior, superior, medial and lateral on the AP and lateral radiographs and on the coronal and sagittal CT reconstructions. The measurements were referenced to this axis. The perpendicular to the glenoid surface was used to define anterior, posterior, medial and lateral on the axillary radiographs and on the axial CT reconstructions and the measurements were also referenced to this axis. For each individual fracture, the CT scan which showed the maximum displacement was selected for each individually analysed fragment. The same researcher (MMdeG) formatted all the image tests and another (AMF) performed all the measurements.

Statistical analysis. This study was designed to compare the final outcome with the pre-injury status as judged by the scores obtained on the day of the injury and the movement and strength of the contralateral shoulder. The variables selected for analysis included pain, the ranges of active elevation, external rotation and internal rotation and the ASES and the DASH scores. For each of these variables, the parameter of interest was defined as the differences between each as measured at the baseline and at 12 months after the fracture. The analysis focused on examining the strength of association of these outcome measurements with age and gender, arm dominance, the pattern of the fracture and measurements of displacement of the fragments on the radiographs and CT scans.

Differences in outcome between the groups of fracture pattern were compared using the chi-squared test for categorical and analysis of variance for continuous variables. 
Table I. Measurements performed both on the CT reconstruction and on radiographs for each patient. The numbers correspond to those in parentheses in Figure 1

\begin{tabular}{|c|c|}
\hline Axial CT reconstruction/axillary radiograph ${ }^{*}$ & Description \\
\hline 1. GT - AS overlapping angle and \% & $\begin{array}{l}\text { Arc of overlapping of the GT over the AS referenced to the center of the AS, } \\
\text { and percentage of the AS covered by the GT }\end{array}$ \\
\hline 2. LT - AS overlapping angle and \% & $\begin{array}{l}\text { Arc of overlapping of the LT over the AS referenced to the centre of the AS, } \\
\text { and percentage of the AS covered by the LT }\end{array}$ \\
\hline 3. GT - glenoid rim distance & Lesser distance between the GT and the posterior glenoid rim \\
\hline 4. $L T$ - glenoid rim distance & Lesser distance between the LT and the anterior glenoid rim \\
\hline 5. GT - LT distance and angle & $\begin{array}{l}\text { Distance between the GT and the LT and arc of displacement between both } \\
\text { tuberosities referenced to the centre of the AS }\end{array}$ \\
\hline 6. GT medial displacement & Medial displacement of the GT \\
\hline 7. LT medial displacement & Medial displacement of the LT \\
\hline 8. Cephalic axis - glenoid axis angle & $\begin{array}{l}\text { Angle between the axis of the humeral AS and the perpendicular to the } \\
\text { glenoid AS }\end{array}$ \\
\hline Cephalic axis - diaphyseal axis angle & $\begin{array}{l}\text { Angle between the axis of the AS and the diaphyseal axis. On radiographs } \\
\text { only }\end{array}$ \\
\hline \multicolumn{2}{|c|}{ Coronal CT reconstruction/anteroposterior radiographs } \\
\hline 1. Cephalodiaphyseal angle & Angle between the diaphyseal axis and the axis of the AS \\
\hline 2. GT - AS & $\begin{array}{l}\text { Distance between the highest points of the AS and the GT perpendicularly } \\
\text { projected on the diaphyseal axis }\end{array}$ \\
\hline 3. Mediolateral translation & $\begin{array}{l}\text { Medial or lateral displacement of the head related to the diaphysis meas- } \\
\text { ured at the medial cortical level }\end{array}$ \\
\hline 4. Medial impaction & Magnitude of medial neck cortex impaction/distraction \\
\hline 5. Lateral impaction & Magnitude of lateral neck cortex impaction/distraction \\
\hline 6. GT acromion distance & Lesser distance between the GT and the acromion \\
\hline 7. AS - acromion distance & Lesser distance between the AS and the acromion \\
\hline \multicolumn{2}{|l|}{ Sagittal CT reconstruction/lateral radiograph } \\
\hline 1. Cephalodiaphyseal angle & Angle between the diaphyseal axis and the axis of the AS \\
\hline 2. Translation in anteroposterior plane & $\begin{array}{l}\text { Anterior or posterior displacement of the head related to the diaphysis } \\
\text { measured at the posterior cortical level }\end{array}$ \\
\hline 3. Flexion - extension of surgical neck & Angle between head and diaphyseal longitudinal axis \\
\hline 4. Anterior impaction & Magnitude of anterior neck cortex impaction/distraction \\
\hline 5. Posterior impaction & Magnitude of posterior neck cortex impaction/distraction \\
\hline Cephalic axis - scapular axis angle & $\begin{array}{l}\text { Angle between the axis of the AS and the longitudinal axis of the scapula. } \\
\text { Only performed on radiographs }\end{array}$ \\
\hline Diaphyseal axis - scapular axis angle & $\begin{array}{l}\text { Angle between the diaphyseal axis and the longitudinal axis of the scapula. } \\
\text { Only performed on radiographs }\end{array}$ \\
\hline
\end{tabular}

* GT, greater tuberosity; AS, articular surface; LT, lesser tuberosity

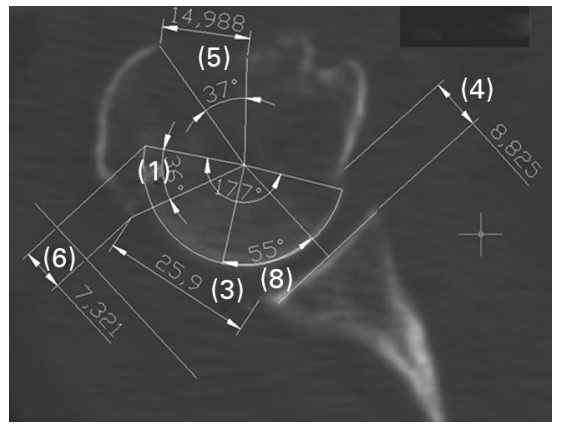

Fig. 1a

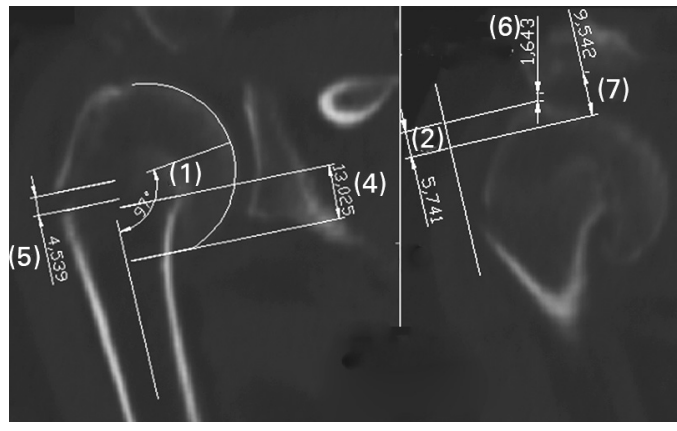

Fig. 1b

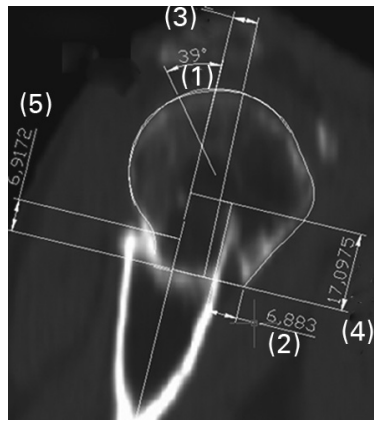

Fig. 1c

Examples on a) an axial CT scan, b) a coronal CT scan and c) a sagittal CT reconstruction scan of computed-assisted measurements performed after correction for magnification. The numbers in parentheses correspond to the measurements given in Table 1 .

Linear regression was used to evaluate the associations between the independent variables and the outcomes. All the variables were initially analysed univariately. Graphic representations of linear regressions were obtained to understand the direction of the relationship between the variables. Next, all the baseline variables were screened before inclusion in the multivariable analysis. We excluded six binary factors with fewer than five observations in one of the levels, seven 


\begin{tabular}{|c|c|c|}
\hline Outcome variable ${ }^{*}$ & Initial status & $\begin{array}{l}\text { Last follow-up } \\
\text { status }\end{array}$ \\
\hline VAS pain (points) & 0.35 (0.0 to 7.5$)$ & $1.95(0.0$ to 8.0$)$ \\
\hline VAS satisfaction (points) & & 7.99 (2.0 to 10.0$)$ \\
\hline Elevation $\left({ }^{\circ}\right)$ & $148(105$ to 180$)$ & 132 (75 to 180$)$ \\
\hline External rotation $\left({ }^{\circ}\right)$ & 55 (20 to 85$)$ & $41(0$ to 85$)$ \\
\hline Internal rotation (spinal levels) ${ }^{\dagger}$ & T7 (L4 to T4) & T10 (gluteus to T4) \\
\hline DASH (points 0 to 100 ) & $16(0$ to 50$)$ & $23(0$ to 70$)$ \\
\hline ASES (points 0 to 100 ) & 91 (48 to 100$)$ & 78 (18 to 100$)$ \\
\hline \multicolumn{3}{|l|}{ Neer's scale (n, \%) } \\
\hline Excellent & & 31 (33.3) \\
\hline Satisfactory & & 39 (41.9) \\
\hline Unsatisfactory & & $23(24.7)$ \\
\hline SF-36 standardised physical component (points) & 46 (20 to 65$)$ & 46 (18 to 64$)$ \\
\hline SF-36 standardised mental component (points) & 49 (12 to 67$)$ & 51 (21 to 68$)$ \\
\hline
\end{tabular}

factors which were measured after the fracture occurred and 13 radiological variables to eliminate redundant information because they were strongly correlated with the CT measurements. Of the remaining independent variables, those with missing observations were imputed using a recursive partitioning model approach in which the values of all the variables which were not missing were used to predict or estimate a particular missing value. The process was repeated for each variable with missing data, each time using the original data to generate the predicted values.

The multivariable analysis used linear regression with stepwise selection. Separate models were used for each outcome. The variables selected by the stepwise selection were reviewed not only for their statistical significance but also for their clinical utility to yield the final models. Separate analyses were carried out for the two most frequent fracture patterns, namely posteromedial impaction fractures $(\mathrm{n}=50)$, and posteromedial impaction fractures with associated fracture of the greater tuberosity, a subgroup of the former $(\mathrm{n}=32)$. The results are given as the mean and SD and a $\mathrm{p}$-value $\leq 0.05$ was considered to be significant.

\section{Results}

Clinical and radiological outcome. Table II shows outcome variables before injury and at the most recent follow-up. Pain was rated as less than 3 by 62 patients $(67 \%)$, between 3 and 6 by $25(27 \%)$, and higher than 6 by six $(6 \%)$.

The reasons for unsatisfactory results according to Neer's scale included pain in three shoulders, loss of movement in 12 and both in eight. Compared with their functional status during the six months before their fracture, 23 patients had lost 10 points or more in their DASH score. One year after the fracture, the mean SF-36 scores were 66 (SD 29) for physical functioning, 79 (SD 36) for physical role, 67 (SD 26) for bodily pain, 65 (SD 25) for general health, 69 (SD 22) for vitality, 90 (SD 18) for social functioning, 82 (SD 37) for emotional role and 70 (SD 18) for mental health.

The radiographs and CT scans at one year showed union of the fracture in 91 patients $(97.8 \%)$. Nonunion at the level of the surgical neck occurred in two. In one this was due to a displaced fracture of the surgical neck, and in the other to a four-part valgus-impacted fracture. There was radiological evidence of avascular necrosis in six patients. This involved less than $20 \%$ of the humeral head in five with minimal symptoms. The remaining patient had avascular necrosis of most of the humeral head and complained of severe pain.

Patterns of fracture. Of the fractures included in the study, $84(90.3 \%)$ could be classified into one of four patterns: posteromedial (varus) impaction in 50 patients $(53.8 \%)$, lateral (valgus) impaction in $13(14.0 \%)$, isolated fractures of the greater tuberosity in $15(16.1 \%)$ and anteromedial impaction in six $(6.5 \%)$ (Fig. 2). The remaining nine fractures $(9.7 \%)$ did not fit into any of the patterns described above with four shoulders having variable non-displaced lines of fracture. One patient who refused surgery had a markedly displaced fracture at the surgical neck, one had impaction of the shaft into the head with undisplaced fractures of both tuberosities, one lateral displacement of the head with no involvement of the tuberosity and extension of the fracture plane along the lateral cortex of the metaphyseal-diaphyseal junction, one anteromedial impaction of the surgical neck with involvement of the greater tuberosity and one had an impression fracture of the articular surface.

Posteromedial (varus) neck impaction $(50,53.8 \%)$. The main plane of the fracture was at the metaphyseal-epiphyseal junction with comminution and impaction of the 


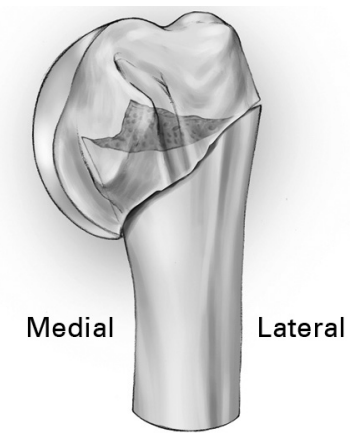

Anterior view

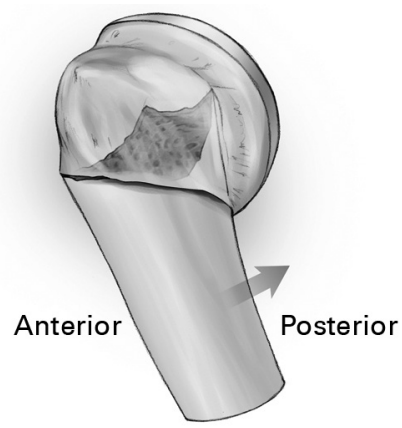

Lateral view

Fig. 2a

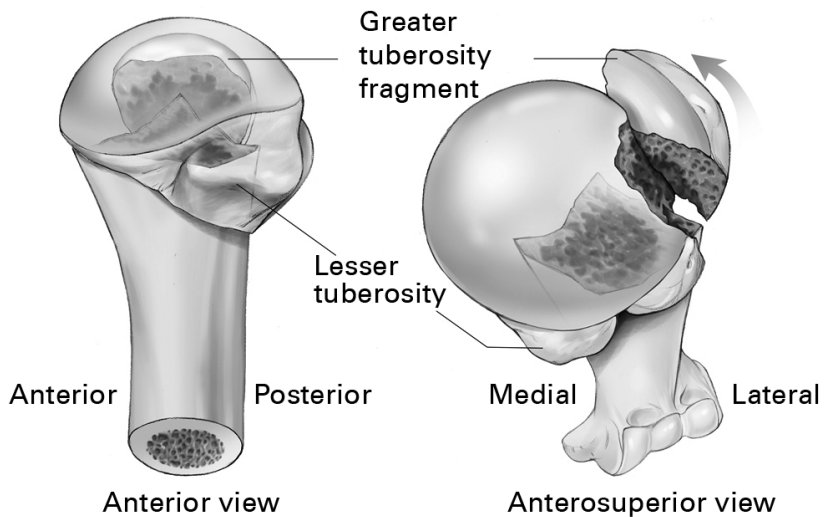

Fig. 2c

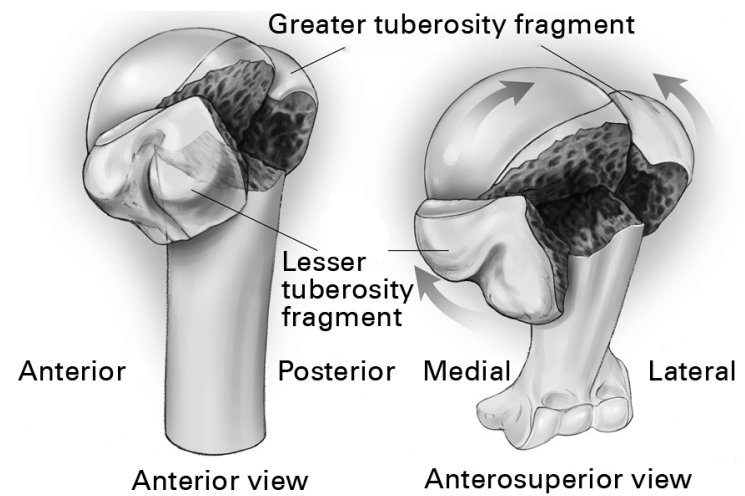

Fig. $2 b$

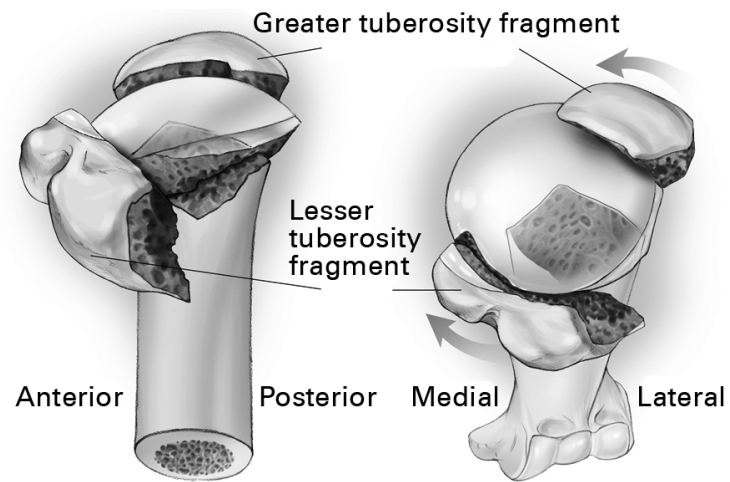

Anterior view

\section{Anterosuperior view}

Fig. 2d

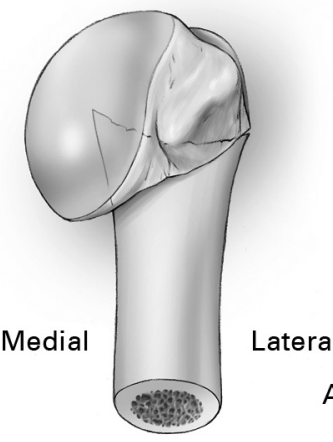

Anterior view

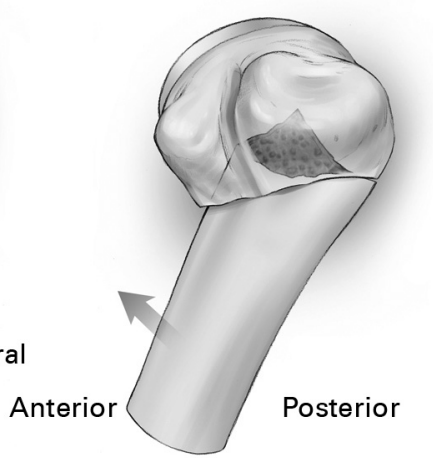

Lateral view

Fig. $2 \mathrm{e}$

Diagrams of some patterns of fracture identified in our study showing a) a posteromedial impaction fracture, b) posteromedial impaction with fracture of both tuberosities, c) a lateral neck impaction fracture with fracture of the greater tuberosity, d) lateral neck impaction with fracture of both tuberosities, e) fracture of the greater tuberosity and f) an anteromedial impaction fracture.

posteromedial aspect of the shaft inside the head. The humeral head was rotated consistently into varus, extension and retroversion. In 18 patients $(19.4 \%)$ this was only the fracture plane, in $28(30.1 \%)$ it was associated with a separate fracture of the greater tuberosity, and in four $(4.3 \%)$ of both tuberosities.
When the greater tuberosity was fractured in this pattern, the fracture plane started lateral to the bicipital groove, leaving up to $50 \%$ of the greater tuberosity in continuity with the bicipital groove and the lesser tuberosity. The fracture plane exited posteriorly through either the greater tuberosity, the junction of the tuberosity with the head or 


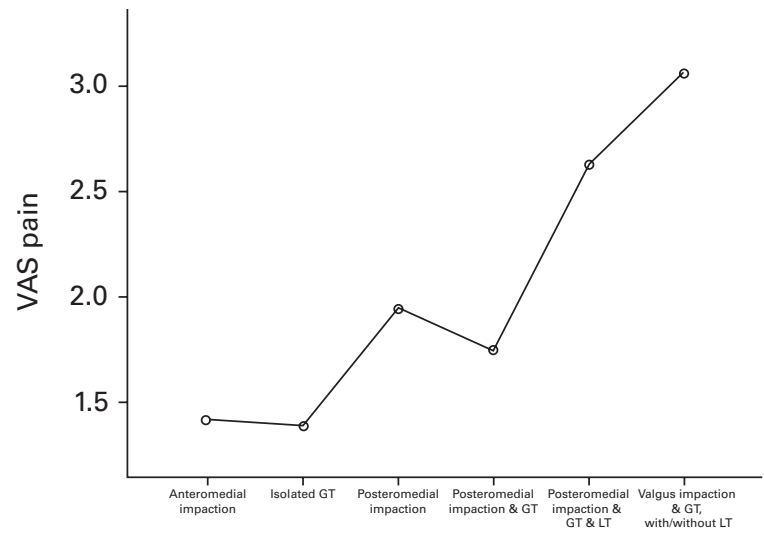

Fracture pattern

Fig. 3a

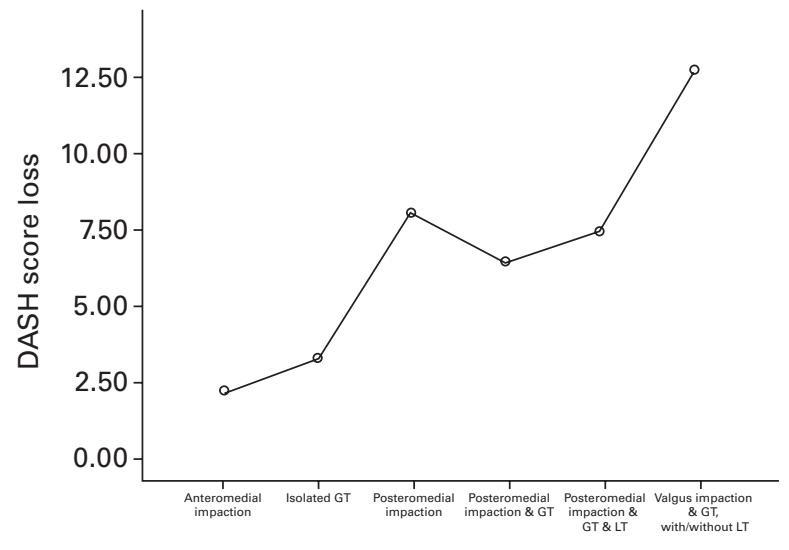

Fracture pattern

Fig. 3c

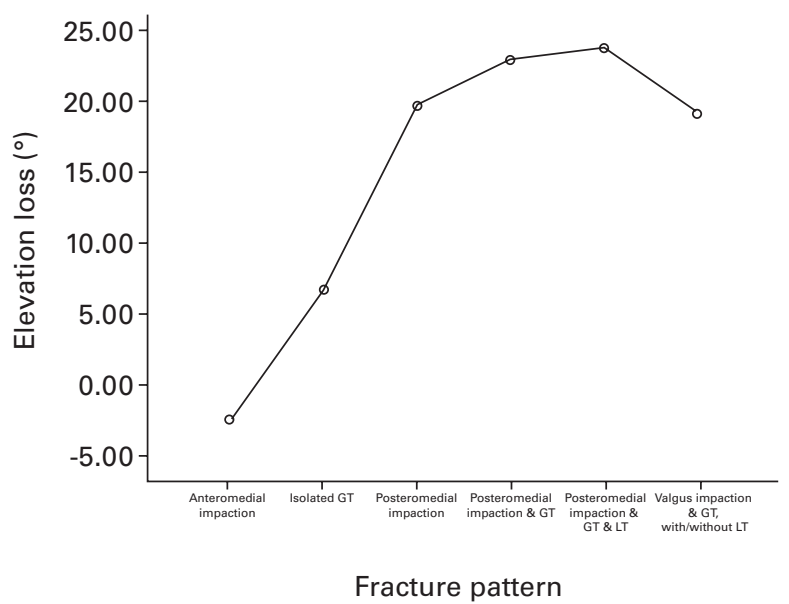

Fig. 3e

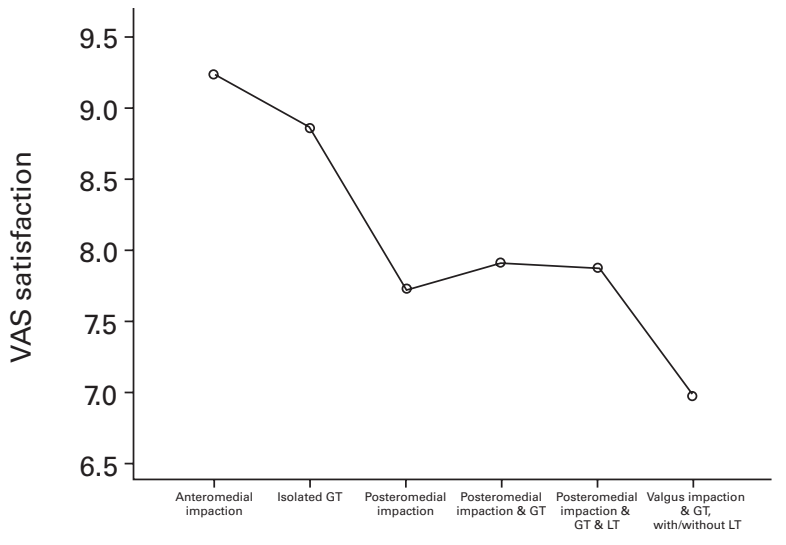

Fracture pattern

Fig. 3b

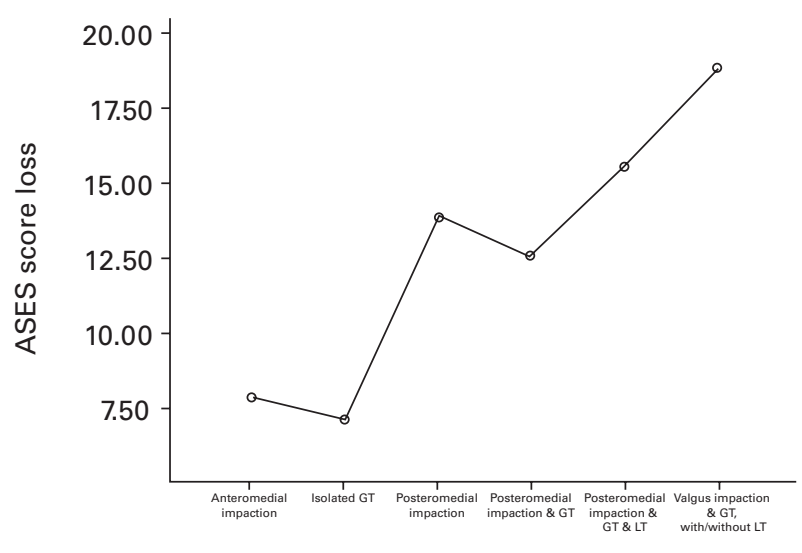

Fracture pattern

Fig. 3d

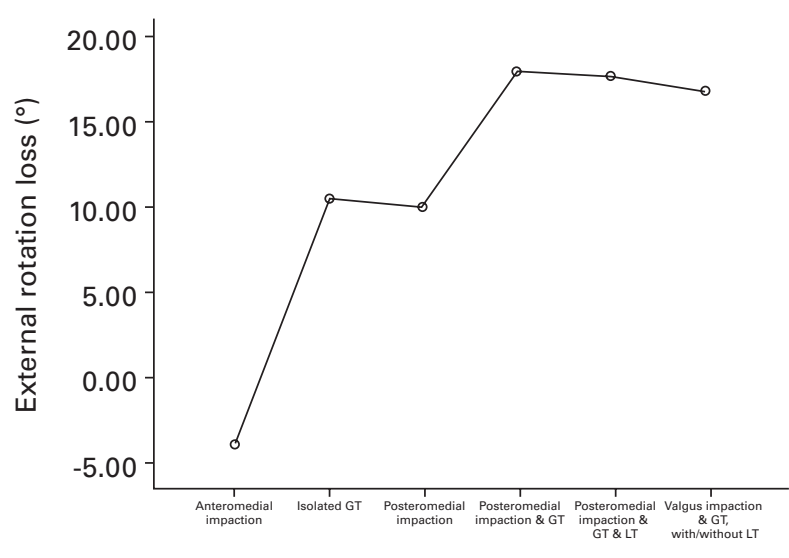

Fracture pattern

Fig. $3 f$

Graphs showing the correlation with the pattern of fracture of a) the visual analogue scale (VAS) for pain, b) the VAS for satisfaction, c) the Disabilities of the Arm, Shoulder and Hand (DASH) score loss, d) the American Shoulder and Elbow Society (ASES) score loss, e) the elevation loss and f) the external rotation loss (GT, greater tuberosity; LT, lesser tuberosity).

occasionally through the articular surface, leaving a variable portion of the posterosuperior articular surface in continuity with the fragment of the greater tuberosity. The greater tuberosity might also be fragmented into many pieces. It displaced consistently posteriorly and medially, with variable overlapping with the posterior articular surface. 
Table III. The clinical value and statistical signification of correlations between measurements performed in CT-3D reconstructions and the outcome variables for all the patients. The model parameters represent the change in outcome from the baseline to follow-up for the given displacement (independent variable)

\begin{tabular}{|c|c|c|c|c|c|c|c|}
\hline \multirow[b]{2}{*}{ Measurement variable ${ }^{*}$} & \multirow[b]{2}{*}{$\begin{array}{l}\text { Measured } \\
\text { displacement }\end{array}$} & \multicolumn{6}{|c|}{ Univariate linear regression model parameter/p-value ${ }^{\dagger}$} \\
\hline & & $\begin{array}{l}\text { ASES change } \\
\text { (points) }\end{array}$ & $\begin{array}{l}\text { DASH change } \\
\text { (points) }\end{array}$ & $\begin{array}{l}\text { Elevation } \\
\text { change }\left({ }^{\circ}\right)\end{array}$ & $\begin{array}{l}\text { Exte } \\
\text { tion }\end{array}$ & $\begin{array}{l}\text { rnal rota- } \\
\text { change }\left({ }^{\circ}\right)\end{array}$ & $\begin{array}{l}\text { Internal rotation } \\
\text { change (spinal levels) }\end{array}$ \\
\hline \multicolumn{8}{|l|}{ Axial CT } \\
\hline AS - Gle angle ${ }^{\ddagger}$ & $>45^{\circ}$ retroversion & $-5.2 p=0.008$ & $+8.7 p=0.05$ & $-14.6 p=0.009$ & -14.9 & $p=0.02$ & $-2.1 p=0.05$ \\
\hline$\%$ GT - AS superposition & $20 \%$ & $-11.0 p<0.001$ & $+8.4 p<0.001$ & $-9.4 p=0.002$ & -12.8 & $3 p<0.001$ & $p=0.06$ \\
\hline Intertuberosity distance (mm) & 10 & $-4.3 p=0.007$ & $+4.0 p=0.001$ & $-3.3 p=0.03$ & -4.3 & $p=0.01$ & $-0.8 p=0.009$ \\
\hline GT medial displacement (mm) & 10 & $-8.8 p<0.001$ & $+5.6 p=0.005$ & $-6.6 p=0.008$ & -11.0 & $p<0.001$ & $p=0.09$ \\
\hline$\%$ LT - AS superposition & $20 \%$ & $p=0.65$ & $p=0.22$ & $p=0.47$ & & $\mathrm{p}=0.39$ & $-6.2 p<0.001$ \\
\hline \multicolumn{8}{|l|}{ Coronal CT } \\
\hline Increase AS - AC distance (mm) & 10 & $-29.7 p<0.001$ & $+20.9 p<0.001$ & $-26.2 p<0.001$ & -21.7 & $\mathrm{p}<<0.001$ & $-3.1 p=0.002$ \\
\hline GT - AS distance (GT above AS) & 10 & $-10.9 p<0.001$ & $+7.8 p=0.002$ & $-15.5 p<0.001$ & -8.8 & $8 p=0.02$ & $-1.5 p=0.02$ \\
\hline Medial impaction (mm) & 10 & $-4.0 p=0.04$ & $p=0.09$ & $-7.5 p<0.001$ & & $p=0.11$ & $p=0.94$ \\
\hline AS - shaft (varus) angulation $\left({ }^{\circ}\right)$ & 20 & $p=0.32$ & $p=0.81$ & $-4.6 p=0.003$ & & $p=0.50$ & $p=0.84$ \\
\hline \multicolumn{8}{|l|}{ Sagittal CT } \\
\hline Extension surgical neck $\left({ }^{\circ}\right)$ & 20 & $\mathrm{p}=0.11$ & $+3.6 p=0.02$ & $-5.6 p=0.003$ & & $p=0.13$ & $p=0.44$ \\
\hline Posterior neck impaction (mm) & 10 & $p=0.07$ & $p=0.07$ & $-8.6 p<0.001$ & -5.9 & $p=0.02$ & $p=0.50$ \\
\hline
\end{tabular}

When fractured, the fragment of the lesser tuberosity included the bicipital groove with a portion of the greater tuberosity as well, and sometimes a portion of the anterior articular surface. This fragment displaced anteriorly and medially with variable overlapping with the anterior articular surface.

Lateral (valgus) neck impaction with fracture of the greater tuberosity $(13,14.0 \%)$. A fracture plane separated the articular surface and the lesser tuberosity from the shaft. The greater tuberosity was fractured from the head and the shaft in all cases in a plane similar to that described above, and was displaced posteriorly and medially leaving space for the head to tilt into valgus. In five of the 13 shoulders there was also a fracture of the lesser tuberosity with a fracture plane and pattern of displacement similar to that described above. Isolated fracture of the greater tuberosity $(15,16.1 \%)$. Only the greater tuberosity was fractured with a plane similar to those described above. There was an associated glenohumeral dislocation in three cases.

Anteromedial neck impaction (6, 6.5\%). The fracture plane separated the shaft from the head and tuberosities at the level of the surgical neck, but the comminution was anteromedial, so that the head rotated into varus, flexion and anteversion. The anterior aspect of the cortex of the shaft impacted into the anteromedial aspect of the head.

Fracture pattern and outcome. The outcome differed depending on the pattern of fracture, with a larger percentage of unsatisfactory results in lateral (valgus) impacted fractures followed by posteromedial (varus) impacted fractures. In $62 \%$ (8 of 13 ) of lateral impacted fractures, $38 \%$ (19 of 50$)$ of posteromedial impaction fractures regardless of tuberosity involvement and in $17 \%$ (5 of 30 ) of all other fractures combined $(\mathrm{p}=0.01)$ there was a 10 point worsening in the DASH score and/or an unsatisfactory Neer result. Lateral (valgus) impacted fractures were three times more likely to result in a 10-point worsening in the DASH score than posteromedial (varus) impacted fractures (odds ratio $3.6,95 \%$ confidence interval 1.01 to 12.8 , $\mathrm{p}=0.048)$. The differences between the fracture patterns were also statistically significant for elevation $(p<0.001)$, internal rotation $(\mathrm{p}=0.04)$ and the Neer modified system ( $\mathrm{p}<0.001$; Fig. 3).

Displacement and outcome. Several measurements of displacement correlated with one or more outcome variables (Table III). That most sensitive to deformity was elevation, being influenced by almost all the measured parameters. A change in shoulder pain was related to the height of the greater tuberosity compared with the height of the articular surface. For each $10 \mathrm{~mm}$ of superior location of the greater tuberosity related to the articular surface, an increase of 0.8 points was observed in the pain VAS $(p=0.05)$. It was also related to the distance of the articular surface from the acromion. For each increase of $10 \mathrm{~mm}$ in this distance there was an increase of 2.6 points in the pain VAS $(\mathrm{p}<0.001)$.

Multivariable models (posteromedial-varus-impaction fractures). Six multivariable models were calculated for the posteromedial (varus) impaction group $(\mathrm{n}=50)$, and five for the posteromedial (varus) impaction and greater tuberosity fracture subgroup $(\mathrm{n}=32)$. Table IV shows the clinical relevance, statistical significance and predictive value of each of the models. 
Table IV. Outcome multivariance models. Each multivariate linear regression model provided the predicted change in the outcome variable for the given displacement defined in the model. The predicted model-based decrease in Disabilities of the Arm, Shoulder and Hand (DASH) after a posteromedial impaction and greater tuberosity fracture with an increase of $5 \mathrm{~mm}$ of the AS-AC distance, a decrease of 5 mm of the LT-Glen distance, and an extension of the neck of $40^{\circ}$ is $7.5-4+12=15.5$ points

\begin{tabular}{|c|c|c|c|c|c|}
\hline Outcome variable $^{*}$ & Measurement variables to $u^{\dagger} e^{\dagger}$ & $\begin{array}{l}\text { Increase in } \\
\text { measurement } \\
\text { variable- } \\
\text { displacement }\end{array}$ & $\begin{array}{l}\text { Resultant } \\
\text { change in } \\
\text { outcome }\end{array}$ & p-value & $\begin{array}{l}\text { Coefficient of } \\
\text { determination }\left(R^{2}\right)\end{array}$ \\
\hline \multicolumn{6}{|l|}{$\begin{array}{l}\text { Posteromedial impaction fracture pattern } \\
(n=50)\end{array}$} \\
\hline Change ASES (points) & AS-AC distance (mm). Coronal CT & $10 \mathrm{~mm}$ & -32.4 & $<0.001$ & 0.40 \\
\hline Change DASH (points) & AS-AC distance $(\mathrm{mm})$. Coronal CT & $10 \mathrm{~mm}$ & 25.6 & $<0.001$ & 0.34 \\
\hline Change elevation $\left({ }^{\circ}\right)$ & $\begin{array}{l}\text { AS-diaphyseal angle. Lateral radio- } \\
\text { graphs }\end{array}$ & $50^{\circ}$ & -9.9 & $<0.004$ & \\
\hline \multirow[t]{2}{*}{ Change external rotation $\left({ }^{\circ}\right)$} & $\begin{array}{l}\text { GT-medial displacement }(\mathrm{mm}) \text {. Axial } \\
\text { CT }(\mathrm{mm})\end{array}$ & 10 & -15 & $<0.001$ & 0.46 \\
\hline & LT-Glen distance (mm). Axial CT & 10 & -20 & $<0.001$ & \\
\hline \multirow[t]{2}{*}{ Change internal rotation (spinal levels) } & LT-AS \% overlapping. Axial CT & 10 & -4.3 & 0.009 & 0.22 \\
\hline & AS-AC distance (mm). Coronal CT & 10 & -2.5 & 0.044 & \\
\hline \multicolumn{6}{|l|}{$\begin{array}{l}\text { Posteromedial impaction and greater } \\
\text { tuberosity fracture }(n=32)\end{array}$} \\
\hline \multirow[t]{2}{*}{ Change ASES (points) } & $\begin{array}{l}\text { Cephalic axis - diaphyseal axis } \\
\text { angle. }{ }^{\ddagger} \text { Axillary radiograph }\end{array}$ & $20^{\circ}$ & -4.6 & 0.037 & 0.39 \\
\hline & AS-AC distance (mm). Coronal CT & 10 & -20.4 & 0.003 & \\
\hline \multirow[t]{3}{*}{ Change DASH (points) } & AS-AC distance (mm). Coronal CT & 10 & 15 & $<0.01$ & 0.57 \\
\hline & LT-Glen distance (mm). Axial CT & 10 & 8 & 0.01 & \\
\hline & Neck extension angle. Sagittal CT & $20^{\circ}$ & 6 & 0.007 & \\
\hline \multirow[t]{2}{*}{ Change elevation $\left({ }^{\circ}\right)$} & $\begin{array}{l}\text { AS-diaphyseal angle. Lateral radio- } \\
\text { graphs }\end{array}$ & 20 & -6.6 & 0.001 & 0.45 \\
\hline & Intertuberosity angle. Axial CT & 20 & -4.2 & 0.004 & \\
\hline \multirow[t]{2}{*}{ Change external rotation $\left({ }^{\circ}\right)$} & $\begin{array}{l}\text { GT medial displacement (mm). Axial } \\
\mathrm{CT}^{\ddagger}\end{array}$ & 10 & 16.8 & $<0.001$ & 0.45 \\
\hline & $\begin{array}{l}\text { Cephalic axis - glenoid axis angle. } \\
\text { Axial CT }\end{array}$ & 20 & 9.6 & 0.013 & \\
\hline Change internal rotation (spinal levels) & $\begin{array}{l}\text { Anterior head translation (mm). } \\
\text { Sagittal CT }\end{array}$ & 10 & -10.5 & $<0.001$ & \\
\hline
\end{tabular}

* ASES, American Shoulder and Elbow Society

† AS, articular surface; AC, acromion; GT, greater tuberosity; LT, lesser tuberosity; Glen, glenoid; lat, lateral

$\ddagger$ measured as increased retroversion

\section{Discussion}

Most of the fractures could be classified into four major patterns. This approach, compared to other classification systems which are more comprehensive but difficult to remember and use, ${ }^{13}$ is much simpler. The important features of each pattern have been described in order to understand better the morphology of the fracture and the diagnostic imaging. The characteristic 3D changes in orientation of the articular surface in each fracture pattern have been incompletely described in the literature. The fracture line separating both tuberosities is usually located in the anterior half of the greater tuberosity as opposed to the bicipital groove as described by Codman ${ }^{14}$ and incorporated into the Neer classification. ${ }^{1}$ The displacement of the tuberosities is mainly medial, with the greater tuberosity located above the articular surface usually as a result of inferior displacement of the latter due to either varus deformity or valgus tilt of the articular surface, as opposed to superior displacement of the tuberosity. ${ }^{15}$ Most of the fractures were impacted at the level of the surgical neck, as has been previously reported. ${ }^{16}$

The outcome was different for each pattern of fracture. The lateral (valgus) impaction group showed the worst results and had a higher rate of complications, accounting for one of the two cases of pseudarthrosis, the only case of global avascular necrosis and two of the five cases of partial necrosis, despite the group comprising only 13 cases $(14.0 \%)$. This finding should be taken into account in decisions for treatment since various publications report a benign evolution of these fractures.,17-19

There is not enough evidence in the literature to support the current recommendation of surgery when displacement is over $1 \mathrm{~cm}$ or $45^{\circ}$, independent of the pattern of the fracture, the fragment involved or the direction of the displacement. ${ }^{1,3,20}$ As seen in Table III, varus deformity was related to pain, probably because of compromise of the subacromial space. Medial displacement of the greater and lesser tuberosities impaired external and internal rotation, 
respectively, because of impingement on the glenoid rim. In posteromedial impaction fractures, the varus deformity, posterior impaction and increased retroversion form the basis of the multivariable model for the increase in the DASH score (Table IV). Since the humerus shortens at the posteromedial head-neck junction, the distance between the articular surface and the acromion is increased. This was strongly related to all the outcome variables and is present consistently in the multivariate models, emphasising its importance.

Multivariate models provided information for predicting outcome for a specific patient based on the pattern of the fracture and displacement of the fragments (Table IV). The influence of fracture morphology on the final results has been weighed and expressed as the coefficient of determination $\left(\mathrm{R}^{2}\right)$. Using the most modern imaging techniques available and dedicated software for measurements, up to $57 \%$ $\left(\mathrm{R}^{2}\right.$ value) of outcome variability could be explained only by the morphology of the fracture. When performing predictions based on these models, it should be taken into account that other factors may influence the results, so that the final outcome could differ from that predicted. Those factors could be related to the individual response to injury, the quality of the bone and soft tissue, the level of compliance with rehabilitation protocols and comorbidities. However, it is important to note that age, gender and arm dominance were all excluded as confounding factors by the multivariate analysis in our study.

Most authors recommend conservative treatment for minimally displaced fractures, and surgery for those most displaced without fragment contact, with associated injury or dislocation to the articular surface. ${ }^{2,21}$ The results of our study indicate that with moderately displaced fractures the pattern should be identified first in order to obtain an overall estimation of the prognosis and the estimated loss of function (DASH) or movement determined. The functional requirements and associated comorbidities of the patient will help in understanding whether or not conservative treatment will be appropriate.

Our study has several weaknesses. Conservative treatment was recommended for all the patients included in our study at the discretion of the on-call orthopaedic team. Some of these patients may have benefited from surgery, but at the time of completion of our study, most surgeons in our hospital were more inclined to recommend conservative treatment for fracture of the proximal humerus. In addition, the sample size of the study was not large enough to represent every single possible fracture of the proximal humerus and the displacement criteria identified may not apply to all types of fracture. Our study also has several strengths. It was prospective. All the patients underwent the same treatment protocol and were evaluated by a single investigator using several validated outcome tools. The same standardised imaging studies were used for all the shoulders. A comprehensive image analysis was carried out and all measurements of displacement were computer-assisted, corrected for magnification and undertaken by a single researcher.
Most fractures of the proximal humerus amenable to conservative treatment follow predictable patterns which may be readily recognised on radiographs of good quality and on CT scans with 3D reconstructions. The pattern of the fracture influences the outcome and the initial displacement of the fragments may be used to predict movement and loss of function.

\section{Listen live}

Listen to the abstract of this article at www.jbjs.org.uk/interactive/audio

We wish to thank the efforts and support of all the members of the Radiodiagnostic and Orthopaedic Surgery Services, and especially the x-ray technicians and colleagues in the Shoulder and Elbow Surgery Unit of La Paz University Hospital.

No benefits in any form have been received or will be received from a commercial party related directly or indirectly to the subject of this article.

\section{References}

1. Neer CS 2nd. Displaced proximal humeral fractures. I: classification and evaluation. J Bone Joint Surg [Am] 1970;52-A:1077-89.

2. Lanting B, MacDermid J, Drosdowech D, Faber KJ. Proximal humeral fractures: a systematic review of treatment modalities. J Shoulder Elbow Surg 2008;17:42-54.

3. Neer CS 2nd. Four-segment classification of proximal humeral fractures: purpose and reliable use. J Shoulder Elbow Surg 2002;11:389-400.

4. Jakob RP, Miniaci A, Anson PS, et al. Four-part valgus impacted fractures of the proximal humerus. J Bone Joint Surg [Br] 1991;73-B:295-8.

5. Edelson G, Kelly I, Vigder F, Reis ND. A three-dimensional classification for fractures of the proximal humerus. J Bone Joint Surg [Br] 2004;86-B:413-25.

6. Zyto K. Non-operative treatment of comminuted fractures of the proximal humerus in elderly patients. Injury 1998;29:349-52.

7. Martínez de la Iglesia J, Dueñas Herrero R, Onís Vilches MC, et al. Spanish language adaptation and validation of the Pfeiffer's questionnaire (SPMSQ) to detect cognitive deterioration in people over 65 years of age. Med Clin (Barc) 2001;117:129-34 (in Spanish).

8. Neer CS 2nd. Shoulder rehabilitation. In: Reines L, ed. Shoulder reconstruction. Philadelphia: WB Saunders Company, 1990:487-533.

9. Slobogean GP, Noonan VK, O'Brien PJ. The reliability and validity of the Disabilities of Arm, Shoulder, and Hand, EuroOol-5D, Health Utilities Index, and Short Form-6D outcome instruments in patients with proximal humeral fractures. J Shoulder Elbow Surg 2010;19:342-8.

10. Ware J, Snow K, Kosinski M, Gandek B. SF-36 Health Survey manual and interpretation guide. Boston: The Health Institute, 1993.

11. Kocher MS, Horan MP, Briggs KK, et al. Reliability, validity, and responsiveness of the American Shoulder and Elbow Surgeons subjective shoulder scale in patients with shoulder instability, rotator cuff disease, and glenohumeral arthritis. J Bone Joint Surg [Am] 2005;87-A:2006-11.

12. Cofield RH. Total shoulder arthroplasty with the Neer prosthesis. J Bone Joint Surg [Am] 1984;66-A:899-906.

13. Müller ME, Nazarian S, Koch P. Classification of AO des fractures. Vol. 1. Berlin: Springer-Verlag, 1987 (in French).

14. Codman EA. Fractures in relation to the subacromial bursa. In: The shoulder: rupture of the supraspinatus tendon and other lesions in or about the subacromial bursa. Vol. 1. Boston: Krieger, 1934:313-31

15. Bono CM, Renard R, Levine RG, Levy AS. Effect of displacement of fractures of the greater tuberosity on the mechanics of the shoulder. J Bone Joint Surg [Br] 2001;83B:1056-62.

16. Court-Brown CM, Garg A, McQueen MM. The epidemiology of proximal humeral fractures. Acta Orthop Scand 2001;72:365-71.

17. Court-Brown CM, Cattermole H, McQueen MM. Impacted valgus fractures (B1.1) of the proximal humerus: the results of non-operative treatment. J Bone Joint Surg $[\mathrm{Br}]$ 2002;84-B:504-8.

18. DeFranco MJ, Brems JJ, Williams GR Jr, lanotti JP. Evaluation and management of valgus impacted four-part proximal humerus fractures. Clin Orthop 2006;442:109-14.

19. Robinson CM, Page RS. Severely impacted valgus proximal humeral fractures: results of operative treatment. J Bone Joint Surg [Am]2003;85-A:1647-55.

20. Handoll HH, Gibson JN, Madhok R. Interventions for treating proximal humeral fractures in adults. Cochrane Database Syst Rev 2003;4:CD000434.

21. Murray IR, Amin AK, White TO, Robinson CM. Proximal humeral fractures: current concepts in classification, treatment and outcomes. J Bone Joint Surg [Br]2011;93-B:1-11. 